Supporting Information for:

\title{
Retarded translocation of nucleic acids through $\alpha$-hemolysin nanopore in the presence of a calcium flux
}

Sha Wang, ${ }^{\# a b}$ Yuqin Wang, \#ab Shuanghong Yan, ${ }^{\text {ab }}$ Xiaoyu Du, ${ }^{\text {ab }}$ Panke Zhang, ${ }^{a}$ HongYuan Chen*a and Shuo Huang ${ }^{* a b}$

[a] State Key Laboratory of Analytical Chemistry for Life Sciences, School of Chemistry and Chemical Engineering, Nanjing University, 210023, Nanjing, China

[b] Chemistry and Biomedicine Innovation Center (ChemBIC), Nanjing University, 210023, Nanjing, China

\# These authors contributed equally to this work

Corresponding Authors:

Prof. Hong-Yuan Chen: hychen@nju.edu.cn

Prof. Shuo Huang: shuo.huang@nju.edu.cn 


\section{Contents}

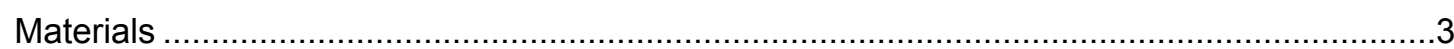

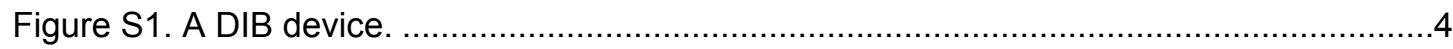

Figure S2. I-V curves of $\alpha-\mathrm{HL}$ with different buffer combinations. ...........................................

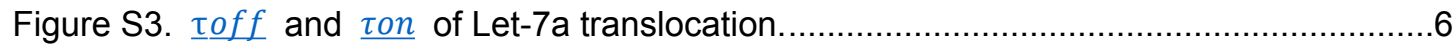

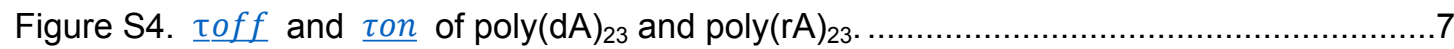

Figure S5. Electrophysiology measurements with $\mathrm{CaCl}_{2}$ in cis. .....................................

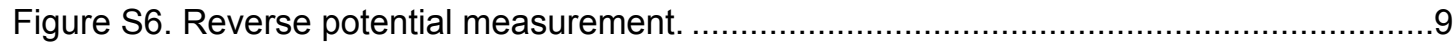

Figure S7. Retarded nucleic acid translocation in the presence of a calcium flux...................10

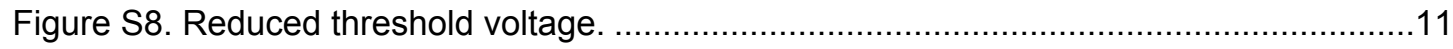

Figure S9. Translocation of RNA homopolymers under different conditions.........................12

Figure S10. Simultaneous detection of RNA homopolymers..........................................13

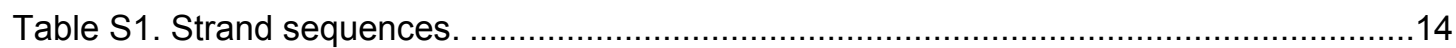

Table S2. $\underline{\tau o f f}$ and $\underline{\tau o n}$ of poly $(\mathrm{dA})_{23}$ in different buffer combinations...........................14

Table S3. $\underline{\tau o f f}$ and $\underline{\tau o n}$ of poly $(\mathrm{rA})_{23}$ in different buffer combinations..............................14

Table S4. The ratio of effective translocation for RNA homopolymers.................................14

Table S5. $\underline{\tau o f f}$ and $\underline{\tau o n}$ of RNA homopolymers translocation.......................................15 


\section{Materials}

Pentane, hexadecane, silicone oil AR20, ethylenediaminetetraacetic acid (EDTA), Triton X-100 were purchased from Sigma-Aldrich. 1,2-diphytanoyl-sn-glycero-3-phosphocholine (DPhPC) was supplied by Avanti Polar Lipids. Fluo-8H sodium electrolyte (Fluo-8) was from AAT Bioquest. 4-(2-hydroxyethyl)-1-piperazine ethanesulfonic acid (HEPES) was from Shanghai Yuanye Bio-Technology (China). Potassium chloride, calcium chloride, sodium chloride, sodium hydrogen phosphate and sodium dihydrogen phosphate were obtained from Aladdin. Chelex 100 resin (biotechnology grade, 100-200 mesh, sodium form), Precision Plus Protein ${ }^{\mathrm{TM}}$ Dual Color Standards and TGX ${ }^{\mathrm{TM}}$ FastCast $^{\mathrm{TM}}$ Acrylamide Kit $(12 \%)$ were from Bio-Rad. Dioxane-free isopropyl- $\beta$-D-thiogalactopyranoside (IPTG), ampicillin sodium and imidazole, trimethylamine methane (tris), glycine and sodium dodecyl sulfate (SDS) were from Solarbio. E. coli strain BL21 (DE3) were from Biomed. Luria-Bertani (LB) broth and LB agar were from Hopebio (China). Hydrochloric acid ( $\mathrm{HCl})$ was from Sinopharm (China). All the items listed above were used as received.

MicroRNA (Let-7a) was custom synthesized by Genscript (New Jersey, USA). DNA and RNA homopolymers (Table S1) were custom synthesized by Sangon Biotechnology (Shanghai, China). All above nucleic acid samples were purified by high-performance liquid chromatography (HPLC) and used without any further purifications. 


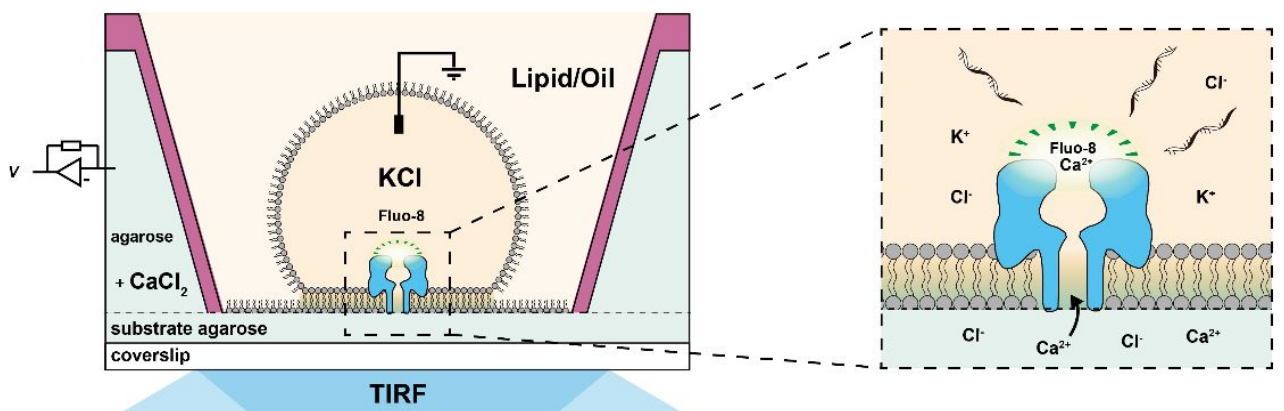

Figure S1. A DIB device. Left: the schematic diagram of a single DIB device. A 60× TIRF objective is used for both illumination and imaging. DIB is formed by placing an aqueous droplet $(\sim 200 \mathrm{~nL})$ on an agarose substrate immersed in a lipid/oil solution. A voltage protocol is applied using $\mathrm{Ag} / \mathrm{AgCl}$ electrodes placed respectively in the agarose substrate and the droplet. Right: a zoomed-in cartoon of oSCR of nucleic acid translocation. $\mathrm{Ca}^{2+}$ in the hydrogel migrates through the nanopore and binds with Fluo-8 in the droplet to form a complex. Upon TIRF illumination, the formed complex around the pore vicinity emits fluorescence, appearing as a fluorescence spot. When a strand of nucleic acid translocates through the pore, the pore is blocked, simultaneously blocking the transport of $\mathrm{Ca}^{2+}$ from trans to cis. Consequently, the fluorescence intensity became diminished, indicating the observation of a translocation event. 


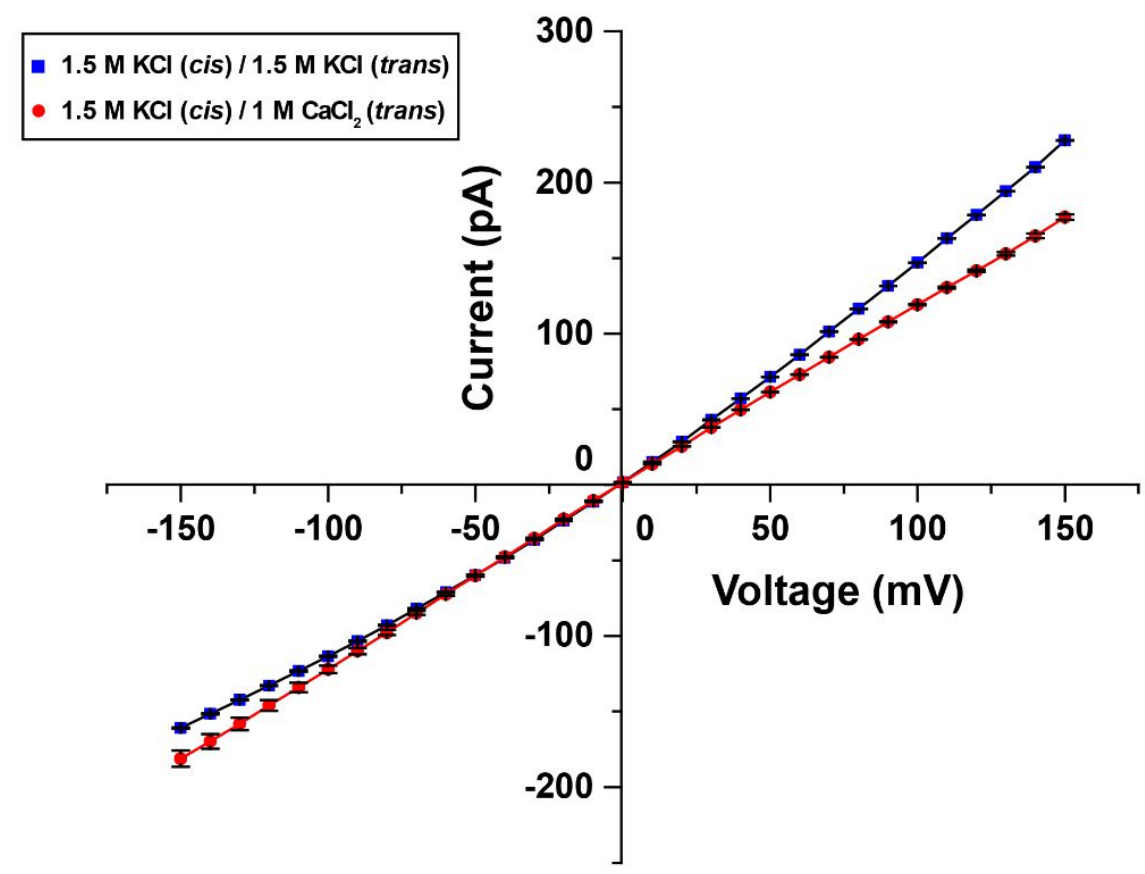

Figure S2. I-V curves of $\alpha-\mathrm{HL}$ with different buffer combinations. Results of I-V curve measurements were acquired with different buffer combinations during electrophysiology measurements. No analyte was involved during the measurements. Error bars were based on three independent measurements $(\mathrm{N}=3)$. The presence of $1 \mathrm{M} \mathrm{CaCl}_{2}$ instead of $1.5 \mathrm{M}$ $\mathrm{KCl}$ in trans results in an obvious drop of open pore current, when a positive bias is applied. 
a)

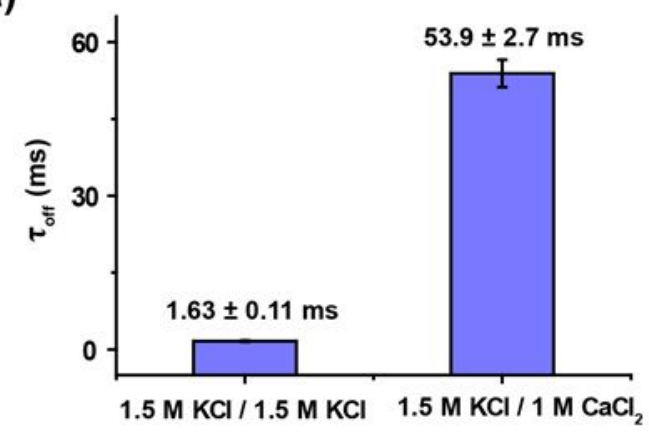

b)

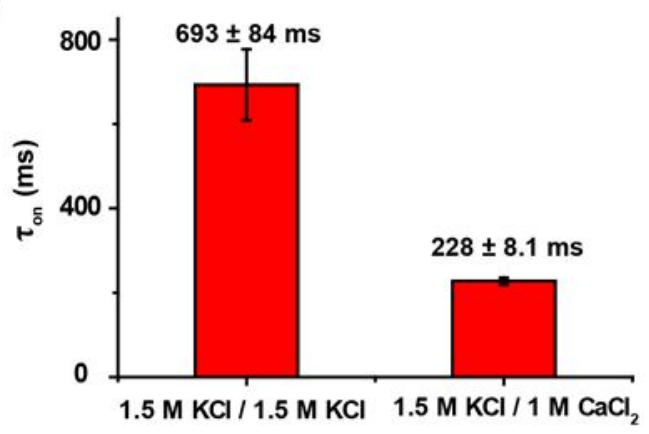

Figure S3. $\tau_{o f f}$ and $\tau_{o n}$ of Let-7a translocation. The mean dwell time $\left(\tau_{o f f}\right)$ a) and the mean inter-event interval $\left(\tau_{o n}\right)$ b) of Let-7a translocation events are demonstrated. Electrophysiology measurements were carried out with a buffer combination of either 1.5 $\mathrm{M} \mathrm{KCl} / 1.5 \mathrm{M} \mathrm{KCl}$ (cis/trans) or 1.5 M KCl/1.0 $\mathrm{M} \mathrm{CaCl}_{2}$ (cis/trans). Let-7a was added to the cis compartment with a $1.0 \mu \mathrm{M}$ final concentration. $\mathrm{A}+100 \mathrm{mV}$ potential was continuously applied. Error bars were based on three independent experiments $(\mathrm{N}=3)$. 
a)

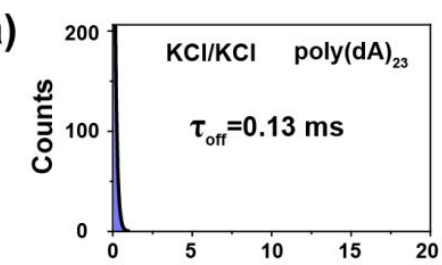

c)

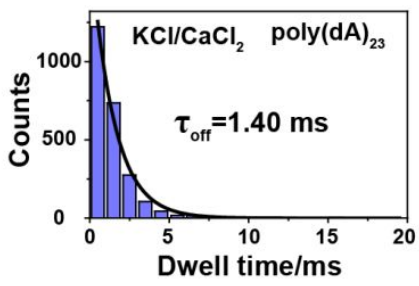

e)

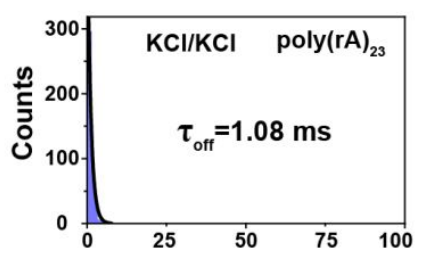

g)

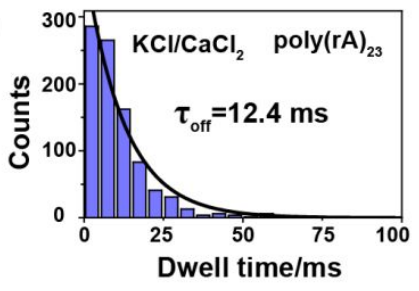

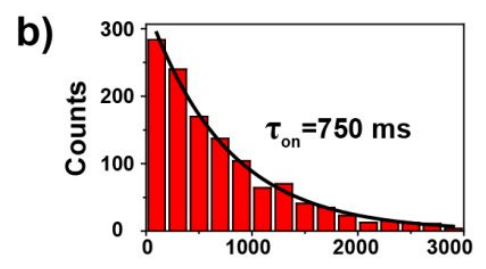
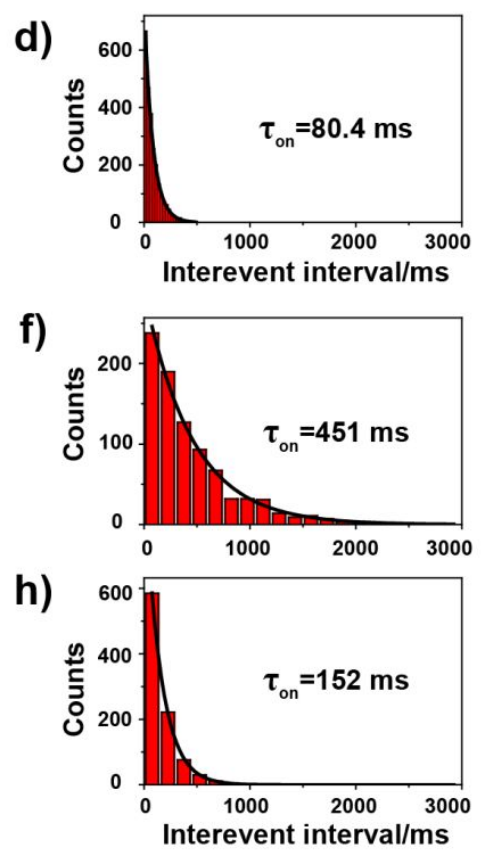

Figure S4. $\tau_{\text {off }}$ and $\tau_{o n}$ of poly(dA $)_{23}$ and poly $(\mathbf{r A})_{23}$. Translocation of poly $(\mathrm{dA})_{23}$ or poly $(\mathrm{rA})_{23}$ was carried out with different combinations of electrolyte buffer. The buffer combination is denoted in the format of cis/trans. Here, the label $\mathrm{KCl}$ represents a buffer of $1.5 \mathrm{M} \mathrm{KCl}$ and10 mM HEPES at $\mathrm{pH}$ 7.0. The label $\mathrm{CaCl}_{2}$ represents a buffer of $1.0 \mathrm{M}$ $\mathrm{CaCl}_{2}$ and $10 \mathrm{mM}$ HEPES at $\mathrm{pH}$ 7.0. Poly $(\mathrm{dA})_{23}$ or poly $(\mathrm{rA})_{23}$ was added to the cis side with a $1.0 \mu \mathrm{M}$ final concentration. $\mathrm{A}+100 \mathrm{mV}$ potential was continuously applied. From the above demonstrated results, the reduction of the translocation speed and the increase of the capture rate were quantitatively verified, as demonstrated by the corresponding histograms a-h). Solid lines are single exponential fits to the histograms. $\tau_{o f f}$ and $\tau_{o n}$ values were derived from the fitting results. 
a)

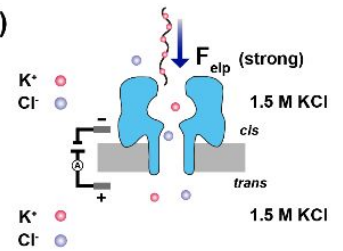

d)

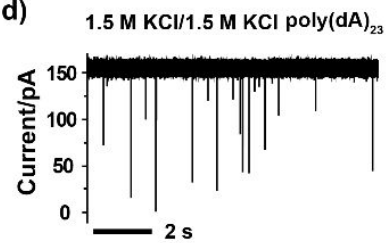

g) $\quad 1.5 \mathrm{M} \mathrm{KCl} / 1.5 \mathrm{M} \mathrm{KCl}$ poly $(\mathrm{rA})_{23}$

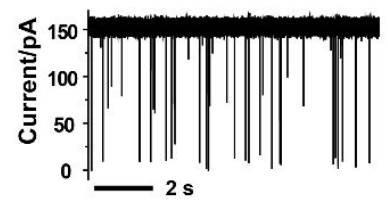

b)

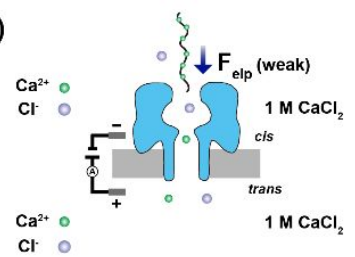

c)

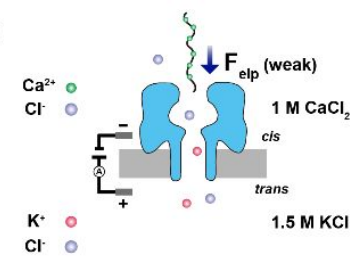

e) $\quad 1 \mathrm{M} \mathrm{CaCl}_{2} / 1 \mathrm{M} \mathrm{CaCl}_{2}$ poly(dA)
$1 \mathrm{M} \mathrm{CaCl}_{2} / 1.5 \mathrm{M} \mathrm{KCl}$ poly$(\mathrm{dA})_{23}$

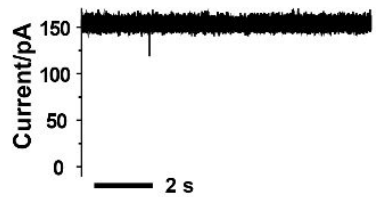

$1 \mathrm{M} \mathrm{CaCl}_{2} / 1.5 \mathrm{M} \mathrm{KCl}$ poly $(\mathrm{rA})_{23}$

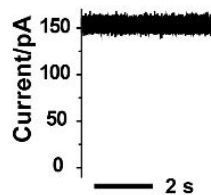

Figure S5. Electrophysiology measurements with $\mathrm{CaCl}_{2}$ in cis. Translocation of poly $(\mathrm{dA})_{23}$ or poly $(\mathrm{rA})_{23}$ was carried out with different combinations of electrolyte buffer. The buffer combination is denoted in the format of cis/trans. Here, the label $1.5 \mathrm{M} \mathrm{KCl}$ represents a buffer of $1.5 \mathrm{M} \mathrm{KCl}$ and $10 \mathrm{mM}$ HEPES at $\mathrm{pH}$ 7.0. Whereas, the label $1.0 \mathrm{M}$ $\mathrm{CaCl}_{2}$ represents a buffer of $1.0 \mathrm{M} \mathrm{CaCl}_{2}$ represents $1.0 \mathrm{M} \mathrm{CaCl}_{2}$ and $10 \mathrm{mM} \mathrm{HEPES}$ at $\mathrm{pH}$ 7.0. Poly $(\mathrm{dA})_{23}$ or poly $(\mathrm{rA})_{23}$ was added to the cis side with a $1.0 \mu \mathrm{M}$ final concentration. A $+100 \mathrm{mV}$ potential was continuously applied. a-c) Schematic diagram of nucleic acids translocation. Representative current traces of $\mathbf{d - f})$ poly $(\mathrm{dA})_{23}$ or $\mathbf{g - i}$ ) poly $(\mathrm{rA})_{23}$ translocation acquired with different buffer combinations. From this set of experiments, it is clearly conclusive that $\mathrm{CaCl}_{2}$ should not be presented in cis, in which the nucleic acid analyte is also placed. The strong coupling between free $\mathrm{Ca}^{2+}$ and the nucleic acids has significantly reduced the effective charge on the nucleic acid analyte, which in turn has significantly reduced the appearance rate of nucleic acid translocation. 


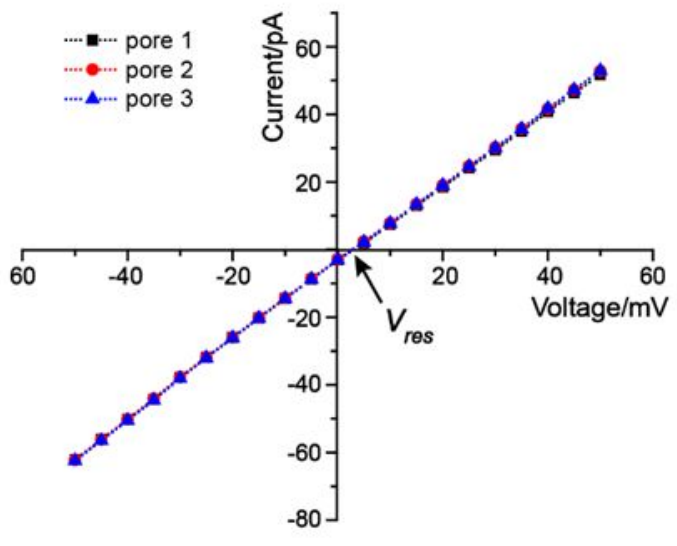

Figure S6. Reverse potential measurement. The nanopore measurement system is first electrically balanced when both sides of the chamber is filled with a $1.5 \mathrm{M}$ potassium chloride buffer. The electrical balance is achieved when the measured current is $0 \mathrm{pA}$ when the applied potential is $0 \mathrm{mV}$. Then the electrolyte buffer in trans is replaced with $1.0 \mathrm{M}$ $\mathrm{CaCl}_{2}$ and an I-V curve is measured. The reverse potential is derived from the I- $\mathrm{V}$ curve, as marked with $V_{\text {res }}$, of which the measured current is $0 \mathrm{pA}$. WT alpha hemolysin is used during the measurement. 


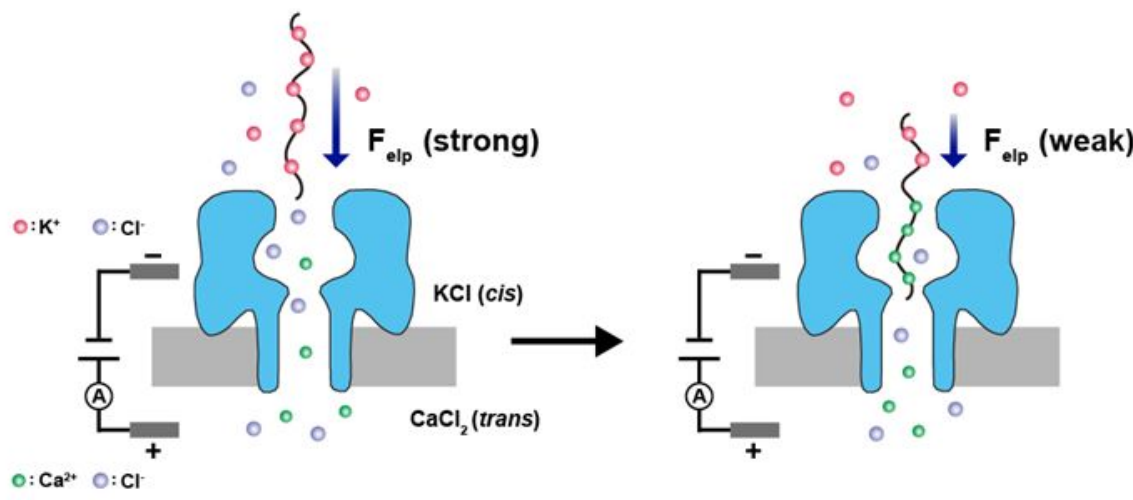

Figure S7. Retarded nucleic acid translocation in the presence of a calcium flux.

During electrophysiology measurements with an asymmetric buffer combination, a $\mathrm{KCl}$ buffer in cis and a $\mathrm{CaCl}_{2}$ buffer in trans, retarded translocation of nucleic acids is observed. In this measurement condition, free $\mathrm{Ca}^{2+}$ distributes inhomogenously around the pore vicinity in the form of a calcium flux. The nucleic acid, which is placed in cis, interacts weakly with $\mathrm{K}^{+}$, but still maintains enough net-negative charges which could be dragged by electrophoretic force $\left(F_{\text {elp }}\right)$ for translocation. The increased concentration of $\mathrm{Ca}^{2+}$ competitively binds with the nucleic acid when it is dragged near the pore, and this further neutralizes the negative charges of the nucleic acid. As a result, the translocation speed is generally retarded and the capture rate is not reduced. 
a)

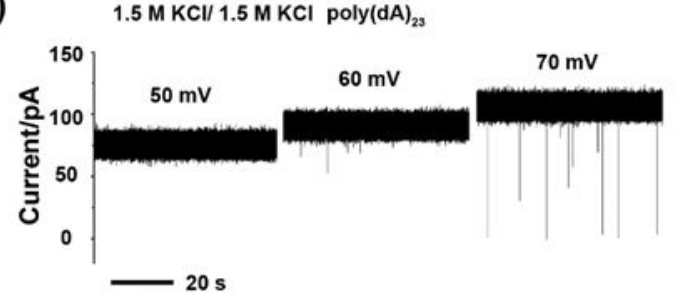

c)

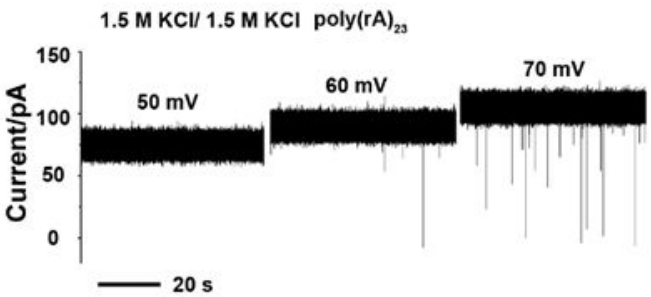

b)

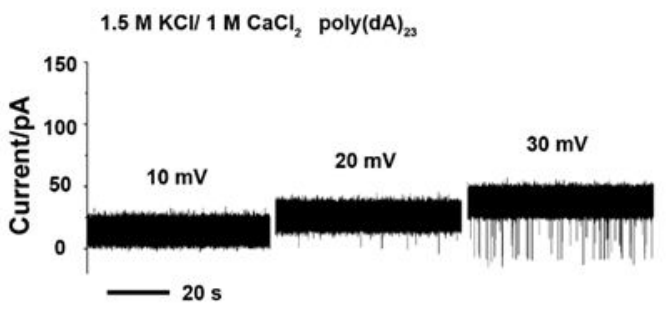

d)

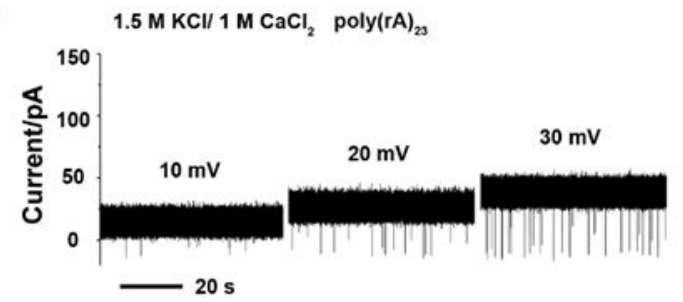

Figure S8. Reduced threshold voltage. The measurements were carried out with a fixed buffer of $1.5 \mathrm{M} \mathrm{KCl}$ and $10 \mathrm{mM}$ HEPES at $\mathrm{pH} 7.0$ in cis but with various buffers in trans. The buffer in trans was either $1.5 \mathrm{M} \mathrm{KCl}$ and10 mM HEPES at pH 7.0 or $1.0 \mathrm{M} \mathrm{CaCl}_{2}$ and $10 \mathrm{mM}$ HEPES at $\mathrm{pH} 7.0$, as labeled in the figures. Poly $(\mathrm{dA})_{23}$ or poly $(\mathrm{rA})_{23}$, which respectively act as representative DNA or RNA analytes, was added to the cis side with a $1.0 \mu \mathrm{M}$ final concentration. With a buffer combination of $1.5 \mathrm{M} \mathrm{KCl} / 1.5 \mathrm{M} \mathrm{KCl}$, a minimum applied voltage to efficiently drive a) poly $(\mathrm{dA})_{23}$ or c) poly $(\mathrm{rA})_{23}$ translocation is around 70 $\mathrm{mV}$. However, with a buffer combination of $1.5 \mathrm{M} \mathrm{KCl} / 1.0 \mathrm{M} \mathrm{CaCl}_{2}$, the minimum applied voltage to efficiently drive b) poly $(\mathrm{dA})_{23}$ or d) poly $(\mathrm{rA})_{23}$ translocation was reduced to around $30 \mathrm{mV}$. 
a)

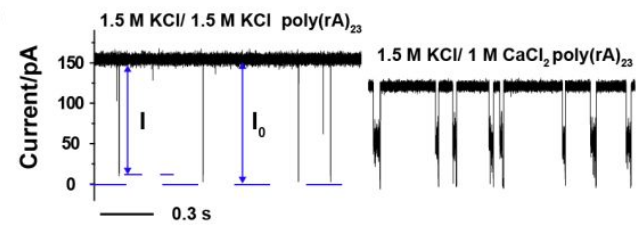

c)

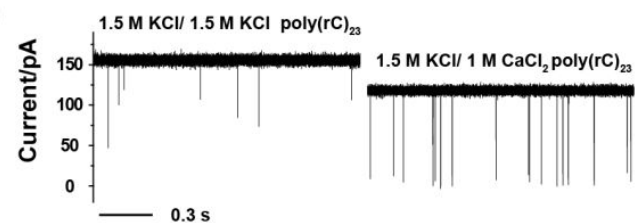

e)

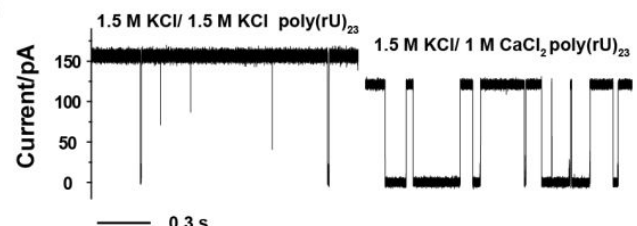

g)

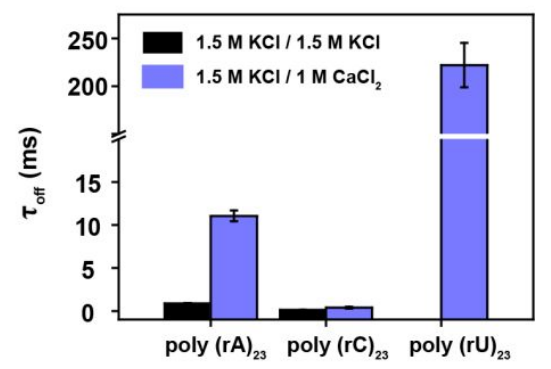

b)

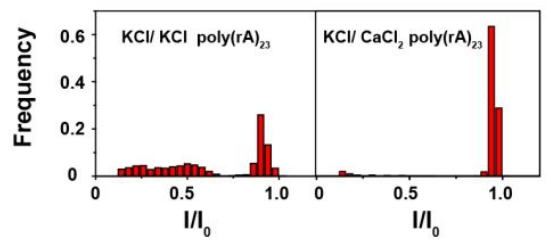

d)

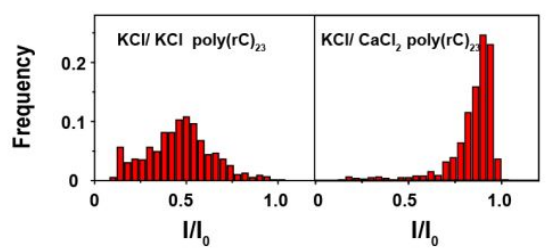

f)

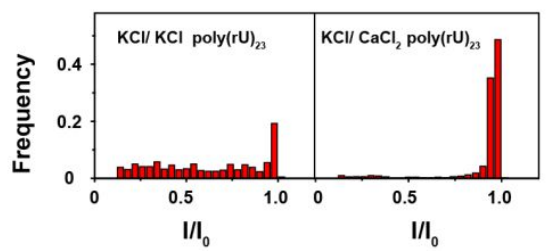

h)

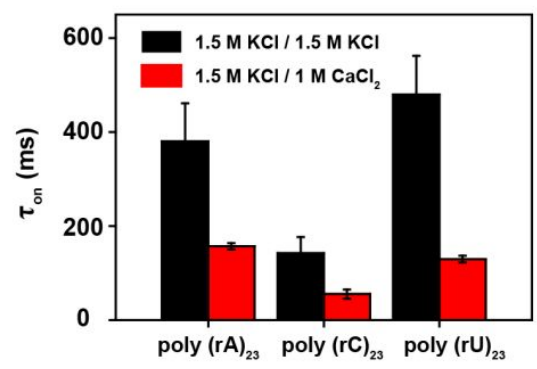

Figure S9. Translocation of RNA homopolymers under different conditions. The measurements were carried out with a fixed buffer of $1.5 \mathrm{M} \mathrm{KCl}$ and $10 \mathrm{mM} \mathrm{HEPES}$ at $\mathrm{pH}$ 7.0 in cis but with various buffers in trans. The buffer in trans was either $1.5 \mathrm{M} \mathrm{KCl}$ and 10 mM HEPES at $\mathrm{pH} 7.0$ or $1.0 \mathrm{M} \mathrm{CaCl}_{2}$ and $10 \mathrm{mM}$ HEPES at $\mathrm{pH} 7.0$, as labeled in the Figures. All measurements were recorded with a $+100 \mathrm{mV}$ applied potential. Representative current traces of a) poly $\left.(\mathrm{rA})_{23}, \mathbf{c}\right)$ poly $(\mathrm{rC})_{23}$ or e) poly $(\mathrm{rU})_{23}$ with different electrolyte buffer combinations are demonstrated. The corresponding histograms of $I / I_{0}$ from measurements taken with b) poly $(\mathrm{rA})_{23}$, d) poly $(\mathrm{rC})_{23}$ or f) poly $\left.(\mathrm{rU})_{23} . \mathbf{g}\right)$ Mean dwell times $\left(\tau_{o f f}\right)$ for poly $(\mathrm{rA})_{23}$, poly $(\mathrm{rC})_{23}$ and poly $(\mathrm{rU})_{23}$ measured with different electrolyte combinations. h) Mean inter-event intervals $\left(\tau_{o n}\right)$ for poly $(\mathrm{rA})_{23}$, poly $(\mathrm{rC})_{23}$ and poly $(\mathrm{rU})_{23}$ measured with different electrolyte combinations. Each RNA homopolymer was added to the cis side with a $1 \mu \mathrm{M}$ final concentration. Error bars were based on three independent experiments $(\mathrm{N}=3)$. 
a)

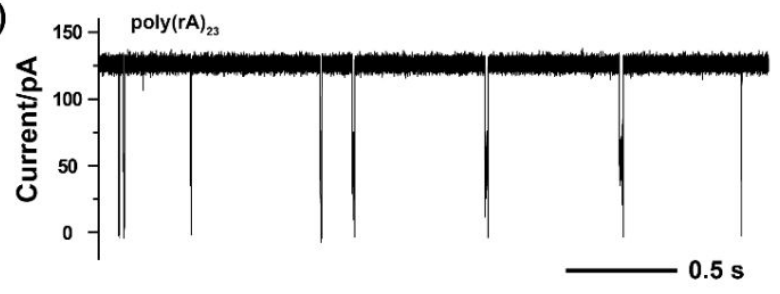

c)

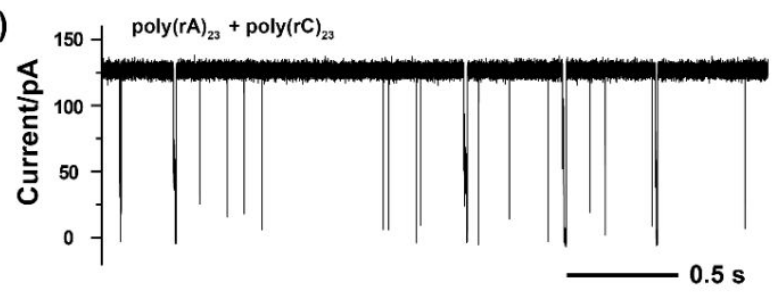

e)

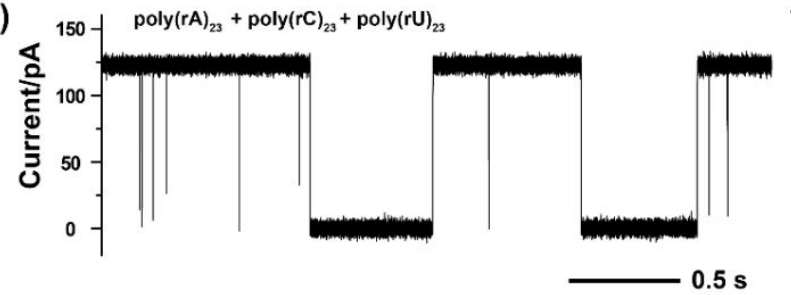

b)

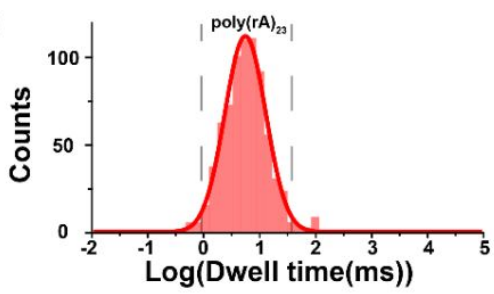

d)

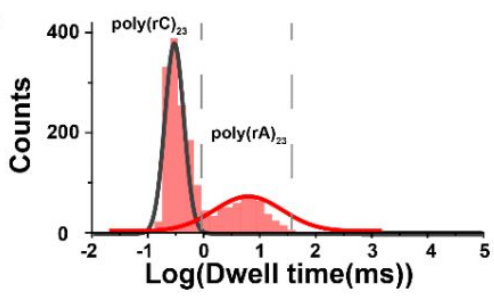

f)

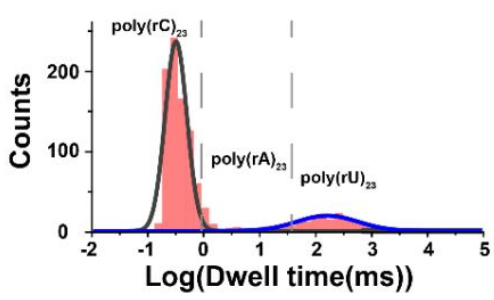

Figure S10. Simultaneous detection of RNA homopolymers. The measurement was carried out with a buffer combination of $(1.5 \mathrm{M} \mathrm{KCl}$ and $10 \mathrm{mM}$ HEPES at $\mathrm{pH} 7.0)$ in cis and $\left(1 \mathrm{M} \mathrm{CaCl}_{2}\right.$ and $10 \mathrm{mM} \mathrm{HEPES}$ at $\left.\mathrm{pH} 7.0\right)$ in trans. A constant $+100 \mathrm{mV}$ potential is applied. RNA homopolymers (poly $(\mathrm{rA})_{23}$, poly $(\mathrm{rC})_{23}$ and poly $\left.(\mathrm{rU})_{23}\right)$ were sequentially added and simultaneously measured with the same pore. a) Representative traces acquired with poly $(\mathrm{rA})_{23}$. Only one type of translocation event were observed, as demonstrated from the trace and the histogram of $\log \left(\tau_{\text {off }}\right)$ in $\left.\mathbf{b} . \mathbf{c}\right)$ The representative trace acquired with poly $(\mathrm{rA})_{23}$ and poly $(\mathrm{rC})_{23}$. Clearly, two populations of events were observed from the trace and the histogram of $\log \left(\tau_{o f f}\right)$ in $\mathbf{d . ~ e ) ~ T h e ~ r e p r e s e n t a t i v e ~ t r a c e s ~}$ acquired with poly $(\mathrm{rA})_{23}$, poly $(\mathrm{rC})_{23}$ and poly $(\mathrm{rU})_{23}$. Translocation of poly $(\mathrm{rU})_{23}$ can be easily recognized by its extremely long dwell time. Only two populations of events can be clearly observed from the histogram of $\log \left(\tau_{\text {off }}\right)$ in $\mathbf{f}$. The disappearance of poly $(\mathrm{rA})_{23}$ events in f) is a consequence of spontaneous hybridization between poly $(\mathrm{rA})_{23}$ and poly $(\mathrm{rU})_{23}$, when simultaneously present in the measurement buffer. Poly $(\mathrm{rA})_{23}$ and poly $(\mathrm{rC})_{23}$ were added to the cis side with a $0.25 \mu \mathrm{M}$ final concentration for each composite. Poly $(\mathrm{rU})_{23}$ was added with a $0.6 \mu \mathrm{M}$ final concentration. 
Table S1. Strand sequences.

\begin{tabular}{c|c}
\hline Strand & Sequence $\left(5^{\prime}-3^{\prime}\right)$ \\
\hline Let-7a & UGAGGUAGUAGGUUGUAUAGUU \\
poly $(\mathrm{dA})_{23}$ & d(AAAAAAAAAAAAAAAAAAAAAA) \\
poly $(\mathrm{rA})_{23}$ & r(AAAAAAAAAAAAAAAAAAAAAAA) \\
poly $(\mathrm{rC})_{23}$ & r(CCCCCCCCCCCCCCCCCCCCCCC) \\
poly $(\mathrm{rU})_{23}$ & r(UUUUUUUUUUUUUUUUUUU \\
\hline
\end{tabular}

Table S2. $\tau_{\text {off }}$ and $\tau_{o n}$ of poly $(\mathrm{dA})_{23}$ in different buffer combinations.

\begin{tabular}{ccccc}
\hline poly $(\mathrm{dA})_{23}$ & $1.5 \mathrm{M} \mathrm{KCl}_{\text {trans }}$ & $1 \mathrm{M} \mathrm{CaCl}_{2 \text { trans }}$ & $2 \mathrm{M} \mathrm{CaCl}_{2 \text { trans }}$ & $3 \mathrm{M} \mathrm{CaCl}_{2 \text { trans }}$ \\
\hline$\tau_{\text {off }}(\mathrm{ms})$ & $0.13 \pm 0.02$ & $1.53 \pm 0.09$ & $2.21 \pm 0.16$ & $3.6 \pm 0.20$ \\
$\tau_{\text {on }}(\mathrm{ms})$ & $627 \pm 104$ & $80.7 \pm 8.6$ & $34.4 \pm 5.9$ & $22.0 \pm 1.8$ \\
\hline
\end{tabular}

The buffer in cis is $1.5 \mathrm{M} \mathrm{KCl}$ and $10 \mathrm{mM}$ HEPES at $\mathrm{pH}$ 7.0. The buffer in trans is described in the table. Poly $(\mathrm{dA})_{23}$ was added to the cis side with a $1.0 \mu \mathrm{M}$ final concentration and a $+100 \mathrm{mV}$ potential was applied continuously.

Table S3. $\tau_{o f f}$ and $\tau_{o n}$ of poly $(\mathrm{rA})_{23}$ in different buffer combinations.

\begin{tabular}{ccccc}
\hline $\operatorname{poly}(\mathrm{rA})_{23}$ & $1.5 \mathrm{M} \mathrm{KCl}_{\text {trans }}$ & $1 \mathrm{M} \mathrm{CaCl}_{2 \text { trans }}$ & $2 \mathrm{M} \mathrm{CaCl}_{2 \text { trans }}$ & $3 \mathrm{M} \mathrm{CaCl}_{2 \text { trans }}$ \\
\hline$\tau_{\text {off }}(\mathrm{ms})$ & $0.88 \pm 0.07$ & $11.1 \pm 0.63$ & $15.0 \pm 0.62$ & $22.8 \pm 0.67$ \\
$\tau_{\text {on }}(\mathrm{ms})$ & $380 \pm 81$ & $157 \pm 6.8$ & $69.2 \pm 8.0$ & $48.1 \pm 3.9$ \\
\hline
\end{tabular}

The buffer in cis is $1.5 \mathrm{M} \mathrm{KCl}$ and $10 \mathrm{mM}$ HEPES at pH 7.0. The buffer in trans is described in the table. Poly $(\mathrm{rA})_{23}$ was added to the cis side with a $1.0 \mu \mathrm{M}$ final concentration and +100 $\mathrm{mV}$ potential was continuously applied.

Table S4. The ratio of effective translocation for RNA homopolymers.

\begin{tabular}{lcc}
\hline & $1.5 \mathrm{M} \mathrm{KCl}($ cis $) / 1.5 \mathrm{M} \mathrm{KCl}$ (trans) & $1.5 \mathrm{M} \mathrm{KCl}($ cis $) / 1 \mathrm{M} \mathrm{CaCl}_{2}$ (trans) \\
\hline poly $(\mathrm{rA})_{23}$ & $(56.6 \pm 8.4) \%$ & $(95.4 \pm 2.6) \%$ \\
$\operatorname{poly}(\mathrm{rC})_{23}$ & $(6.31 \pm 1.6) \%$ & $(92.6 \pm 1.9) \%$ \\
$\operatorname{poly}(\mathrm{rU})_{23}$ & $(40.2 \pm 3.6) \%$ & $(91.1 \pm 2.4) \%$
\end{tabular}

RNA homopolymers were added to the cis side with a $1 \mu \mathrm{M}$ final concentration. The buffer 
used was $10 \mathrm{mM}$ HEPES at $\mathrm{pH} 7.0$ and a $+100 \mathrm{mV}$ potential was continuously applied. Effective translocation is defined as events with a deep enough percentage blockage $\left(\mathrm{l} / \mathrm{I}_{0}>70 \%\right)$

Table S5. $\tau_{o f f}$ and $\tau_{o n}$ of RNA homopolymers translocation.

\begin{tabular}{c|cc|cc}
\hline & \multicolumn{2}{|c|}{$1.5 \mathrm{KCl}($ cis $) / 1.5 \mathrm{M} \mathrm{KCl}($ trans $)$} & \multicolumn{2}{c}{$1.5 \mathrm{M} \mathrm{KCl}($ cis $) / 1 \mathrm{M} \mathrm{CaCl}_{2}$ (trans) } \\
\cline { 2 - 5 } & $\tau_{\text {off }}(\mathrm{ms})$ & $\tau_{\text {on }}(\mathrm{ms})$ & $\tau_{\text {off }}(\mathrm{ms})$ & $\tau_{\text {on }}(\mathrm{ms})$ \\
\hline $\operatorname{poly}(\mathrm{rA})_{23}$ & $0.88 \pm 0.07$ & $380 \pm 81$ & $11.1 \pm 0.63$ & $157 \pm 6.8$ \\
$\operatorname{poly}(\mathrm{rC})_{23}$ & $0.12 \pm 0.03$ & $142 \pm 34$ & $0.39 \pm 0.10$ & $55.4 \pm 9.7$ \\
$\operatorname{poly}(\mathrm{rU})_{23}$ & & $480 \pm 82$ & $222 \pm 23$ & $130 \pm 7.3$ \\
\hline
\end{tabular}

RNA homopolymers were added to the cis side with a $1 \mu \mathrm{M}$ final concentration. The buffer used was $10 \mathrm{mM}$ HEPES at $\mathrm{pH} 7.0$ and a $+100 \mathrm{mV}$ potential was continuously applied. 